\title{
ANALYSES OF WASTE PRODUCTS OBTAINED BY LASER CUTTING OF AW-3103 ALUMINIUM ALLOY
}

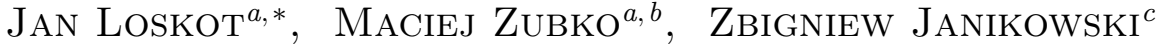 \\ ${ }^{a}$ University of Hradec Králové, Department of Physics, Rokitanského 62, 50003 Hradec Králové, Czech Republic \\ ${ }^{b}$ University of Silesia in Katowice, Institute of Materials Engineering, 75 Pułku Piechoty 1a, 41500 Chorzów, \\ Poland \\ c "Silver" PPHU, ul. Rymera 4, 44270 Rybnik, Poland \\ * corresponding author: jan.loskot@uhk.cz
}

ABstract. In the presented research, the methods of scanning electron microscopy, energy-dispersive $\mathrm{X}$-ray spectroscopy, X-ray diffraction and transmission electron microscopy were applied to analyse the powder waste obtained by cutting of AW-3103 aluminium alloy using a fibre laser. The scanning electron microscopy allows to analyse the morphology of the waste microparticles, the energy-dispersive X-ray spectroscopy revealed their chemical composition, which was compared with the composition of the original cut material. In the waste powder, mainly plate-like particles were observed that contain almost pure aluminium. X-ray powder diffraction measurements confirmed that the waste powder is composed of aluminium phase with only a slight presence of other phases (magnetite, austenite and graphite) and the transmission electron microscopy revealed the presence of nanoscale particles in this waste powder. Furthermore, it was found that the average size of the microparticles depends on the thickness of the cut material: particles obtained from a thicker workpiece were substantially bigger than those obtained from the thinner material. On the contrary, the dimensions of the workpiece have only a little impact on the particles' shape and no significant influence on their chemical composition. The results also suggest that the microparticles could be used as an input material for powder metallurgy. But there is also a certain health risk connected with inhalation of such tiny particles, especially the nanoparticles, which can penetrate deep into the human pulmonary system.

KEYWORDs: Laser cutting, aluminium alloy, waste products, scanning electron microscopy, X-ray diffraction.

\section{INTRODUCTION}

Over the last few decades, a considerable number of laser beam machining (LBM) technologies have been developed, offering a wide range of applications [1, 2. A substantial advantage of the LBM is that it does not cause mechanically induced damage of the processed material, machine vibrations and tool wear. Especially suitable for the LBM are materials with a high degree of hardness or brittleness, as well as materials having low thermal conductivity and diffusivity [1].

One of the LBM technologies is laser cutting, which is often used in machine industry for processing almost all types of engineering materials, thus offering many applications too [3]. A widespread usage of this technology is machining of metallic materials, such as steels or non-ferrous metal alloys. Laser cutting enables to produce components of various shapes with a clean cut edge [4, but it is also applied, for example, in waste management where it serves to disassemble discarded products [5, 6. It is worth mentioning that laser beam irradiation is also used in other manufacturing technologies, for example, in welding processes [7, sintering, turning, milling [1] or in laser surface alloying, which can enhance material properties (e. g., it can improve its hardness) [8].
During the laser cutting process, the material to be cut is targeted by a high power laser beam. When the laser beam hits a metal surface, the local temperature raises to the melting point, which results in the material melting at this place. This liquid film is subsequently ejected from the kerf area to the surrounding environment by the assist gas (usually compressed air, nitrogen or argon) which is blown out from a nozzle of the cutting head.

It is worth mentioning that, on the one hand, the liquid layer becomes thicker with an increasing laser output power, because the energy absorbed is higher and thus the melting rate of the solid substrate increases. On the other hand, the liquid layer thickness decreases with an increasing assist gas velocity. This is caused by the shearing force between the assist gas and the melt surface, which accelerates the melt flow out of the workpiece in the direction of the assist gas. The assist gas also reduces the melt surface temperature due to convective heat transfer 9 .

A typical imperfection generated on the workpiece cut edge is dross. It arises as a consequence of the molten material agglomeration at the lower wedge of the cut edge [10. The dross formation depends on the cutting properties (such as assist gas velocity or kerf size), as well as on the properties of the liquid 
film (viscosity, density, surface tension) 99. The more the molten material flows, the larger the droplet size is. If the droplets are close enough to each other, they can merge into larger drops [10].

While solidifying, the droplets are subjected to the shear force caused by the assist gas. It can cause their deformation, break-up or detachment followed by a subsequent ejection from the workpiece. The process of detachment occurs mostly in close proximity to the cutting front, because the liquid velocity is higher here (thanks to its lower viscosity), whereas its surface tension is lower [10].

In [11, another mechanism of the droplet formation is described. It is the so-called Kelvin-Helmholtz instability, which occurs on the interface of two fluids (in our case the assist gas and the molten material) in shear. This instability causes surface waves, which lead to turbulences of the liquid. As a consequence, metal drops can eventually break off from the liquid surface. The size of the resulting particle is of the order of the surface wave wavelength, which is comparable to the depth of the affected liquid. Particles formed by this mechanism are typically small as compared to the particles formed from dross at the lower wedge of the cut edge.

While the ejected metal droplets are passing through the atmosphere, they solidify again and become powder waste that is commonly thrown away [12]. This powder consists of various microand nanoparticles whose characteristics depend on the kind of the cut material and on the type of the used laser and technological parameters of the cutting process.

When compared to conventional machining technologies (such as sawing or chipboard milling), laser cutting produces less cutting dross, because the kerfs created by the laser beam are quite narrow [13. Even so, a considerable amount of dross is produced by laser cutting of metallic materials this way [12. This waste material is a source of difficulties for companies, which are performing laser cutting, because there is still not enough available possibilities to use this waste material and it is problematic to dispose of it legally.

Recently, there has been a growing pressure on reusing waste generated by industrial production in developed countries. Several studies concerning the possible usage of powder waste produced by laser cutting have been conducted. It was found out that small dross particles obtained by laser cutting of metals can serve as an input material for powder metallurgy [14], there is also a potential to use them as a carrier for various substances, such as pesticides, fertilizers or medical drugs [12]. A considerable attention is also paid to health hazards arising from tiny dross particles generated by laser cutting and related material processing methods [13, 15.

In this research, we analysed waste particles generated during laser cutting of a widely used AW-3103 aluminium alloy. Results of this study should provide

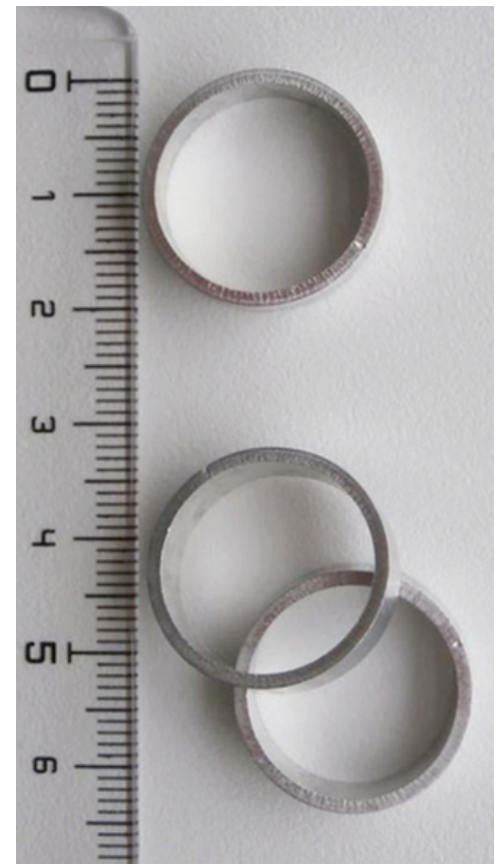

Figure 1. Rings cut from the thicker tube.

knowledge for a further research of reusing these waste materials as well as for an assessment of health risks connected especially with inhalation of such small particles.

\section{MATERIAL AND METHODS}

Research samples were prepared by laser cutting of AW-3103 alloy tubes. The cutting process was done using the BLM LT 5 automated fibre laser cutting machine equipped with YLR-1000-MM-WC multimode fibre laser. The laser worked at a wavelength of $1070 \mathrm{~nm}$ and its average power was $300 \mathrm{~W}$. The laser beam diameter during the cutting process was $100 \mu \mathrm{m}$, the cutting speed was $0.22 \mathrm{~m} \cdot \mathrm{s}^{-1}$. To prevent oxidation of the cut material, the cutting process was performed in a protective nitrogen atmosphere: the gaseous nitrogen was blown out from a nozzle to the cutting area. The pressure at the nozzle was 12 bar.

Tubes of two different sizes were cut: a thicker tube with an outer diameter of $20 \mathrm{~mm}$ and a wall width of $1.2 \mathrm{~mm}$, and a thinner tube with an outer diameter of $16 \mathrm{~mm}$ and a wall width of $1.3 \mathrm{~mm}$. Both tubes were cut in a plane perpendicular to the axis of symmetry, so that small rings were cut from them. The waste powder generated during the cutting process was subsequently collected. Some of the cut rings are shown in Figure 1 an example of the powder sample is given in Figure 2

The morphology of the powder waste particles was studied by using the Hitachi FlexSEM 1000 scanning electron microscope (SEM); the used accelerating voltage was $20 \mathrm{kV}$. The SEM was equipped with an $\mathrm{X}$ ray energy-dispersive spectroscopy (EDS) attachment from Oxford Instruments (detection area: $30 \mathrm{~mm}^{2}$, type of detector: SDD - Silicon Drift Detector, energy 


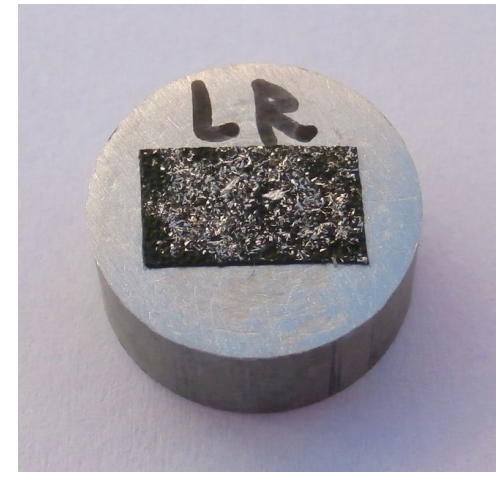

FiguRE 2. Metal waste powder collected after laser cutting (stub diameter is $12 \mathrm{~mm}$ ).

resolution: $137 \mathrm{eV}$ at $\mathrm{Mn}_{\alpha}$ line), which was used for elemental composition analysis of the samples.

Measurements of the smallest particles were done using the JEOL JEM-3010 high-resolution transmission electron microscope (TEM) operated at $300 \mathrm{kV}$ acceleration voltage, equipped with a CCD camera Gatan $2 \mathrm{k} \times 2 \mathrm{k}$ Orius ${ }^{\mathrm{TM}} 833$ SC200D. To get the smallest particles from the powder material, the powder was dispersed in isopropanol solution and a 30-minute ultrasonic bath was applied. This suspension was then left still for approximately 2 minutes, so heavy particles could sediment to the bottom of the flask. After that, samples of the liquid with remaining tiny particles were taken from the flask by a pipette and deposited on a carbon grid for the measurements.

The structural analysis of the waste powder was based on X-ray powder diffraction (XRD) measurements. For this purpose, Malvern Panalytical Empyrean diffractometer with a copper anode $\left(\mathrm{CuK}_{\alpha}\right.$ : $\lambda=1.5418 \AA$ ) and with the PIXcel3D detector was used. The working current was $30 \mathrm{~mA}$ and the working voltage was $40 \mathrm{kV}$. The XRD measurements were performed in a range of angles $2 \theta=10 \div 110^{\circ}$, the step size was $0.026^{\circ}$.

\section{Results And Discussion}

\subsection{Microscopic OBSERVATIONS}

The particles obtained from both tubes were studied using the SEM in secondary electrons mode. As can be seen in Figure 3 most of the particles are platelike, but smaller bumpy spheres were also found in the powders (Fig. 4).

The particle image analysis was done in ImageJ software. Table 1 shows mean values and medians of Feret's diameter, solidity, circularity and roundness of the particles (these characteristics were calculated according to their definitions in [16]). Statistical distributions of these characteristics are given in Figure 5

This analysis showed that the waste particles are quite solid, but mostly not very circular. Particles obtained from the thicker tube are substantially bigger on average compared with the particles from the thinner tube, whereas their mean solidity, roundness and circularity are not so much higher. This suggests that the dimensions of the original aluminium material have quite a significant impact on the waste particles' size, but only a little impact on their shape. The observed dependency of particles' size on the original material thickness is consistent with findings of the study [17, where particles generated during laser cutting of mild and stainless steels were examined. In that case, plates of thickness 1, 2 and $3 \mathrm{~mm}$ (for mild steel also $4 \mathrm{~mm}$ ) were cut at a comparable laser power $(900 \mathrm{~W})$ and it was found that the particles' size tend to increase with increasing thickness of the cut material too. According to [17, this general trend can be attributed to the following factors:

(1.) The vertical flow of the assist gas diminishes as the depth of the cut increases. Therefore, the shearing action of the gas is reduced, which suppresses the formation of the tiniest particles.

(2.) With increasing the thickness of the cut piece, the average temperature of the molten material in the kerf decreases. Due to this, the surface tension of the molten material gets higher, which results in the formation of bigger particles.

The observed microparticles were compared to the results of studies dealing with microparticles generated during laser cutting of steels. The most obvious difference is in the shape: AW-3103 alloy particles are mostly plate-like, whereas particles from mild steel as well as stainless steel are spherical [9, 11, 12, 17. 19]. The reason might be that the steel particles had solidified before they fell to the ground, while the AW-3103 alloy particles had not been solidified enough at the moment of their impact, so they became plastically deformed.

Regarding the sizes of microparticles, laser cutting of $2 \mathrm{~mm}$ thick $0.25 \% \mathrm{C}$ mild steel samples under various processing parameters produced particles with a mean diameters of $150 \mu \mathrm{m}$ [11. The study [1] also showed that the particle size distribution depends on the laser power and cutting speed. The mean Feret's diameter of AW-3103 alloy particles is somewhat smaller for both the thicker tube $(114 \mu \mathrm{m})$ and the thinner tube $(81 \mu \mathrm{m})$, but this has to be considered carefully due to the different sample thickness and different processing parameters used.

Anyway, statistical distributions of Feret's diameters show that the sizes of particles from both aluminium tubes should be suitable for powder metallurgy [20, 21]. Particles in a desired size range can easily be obtained from the waste powder by using laboratory sieves with appropriate mesh dimensions.

Using the TEM, nanoparticles with Feret's diameters mostly in the range from 20 to $80 \mathrm{~nm}$ were also found in the waste powder. All observed nanoparticles were below $150 \mathrm{~nm}$ in Feret's diameter. A TEM image of these nanoparticles is shown in Figure 6 For a comparison, the study [19] describes nanoparticles produced by laser cutting of $6.35 \mathrm{~mm}$ thick SAE-1010 

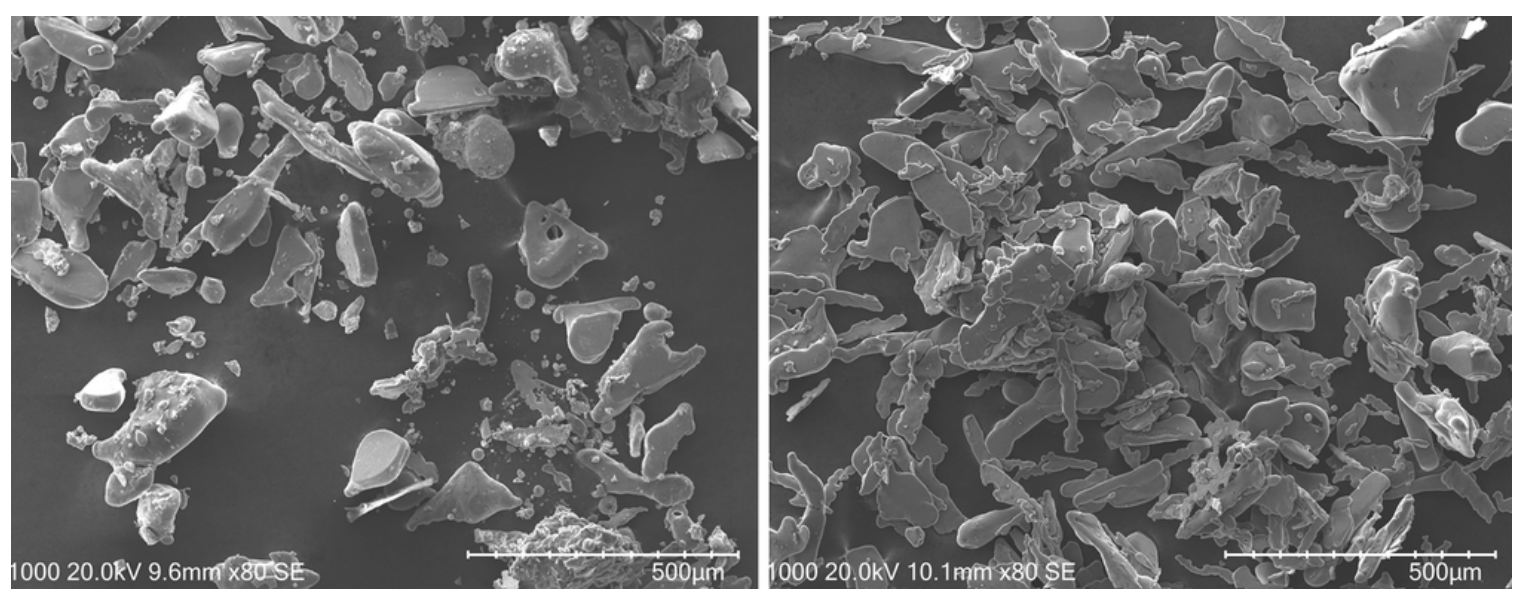

Figure 3. Metal powders produced by laser cutting of the thicker tube (left) and the thinner tube (right).
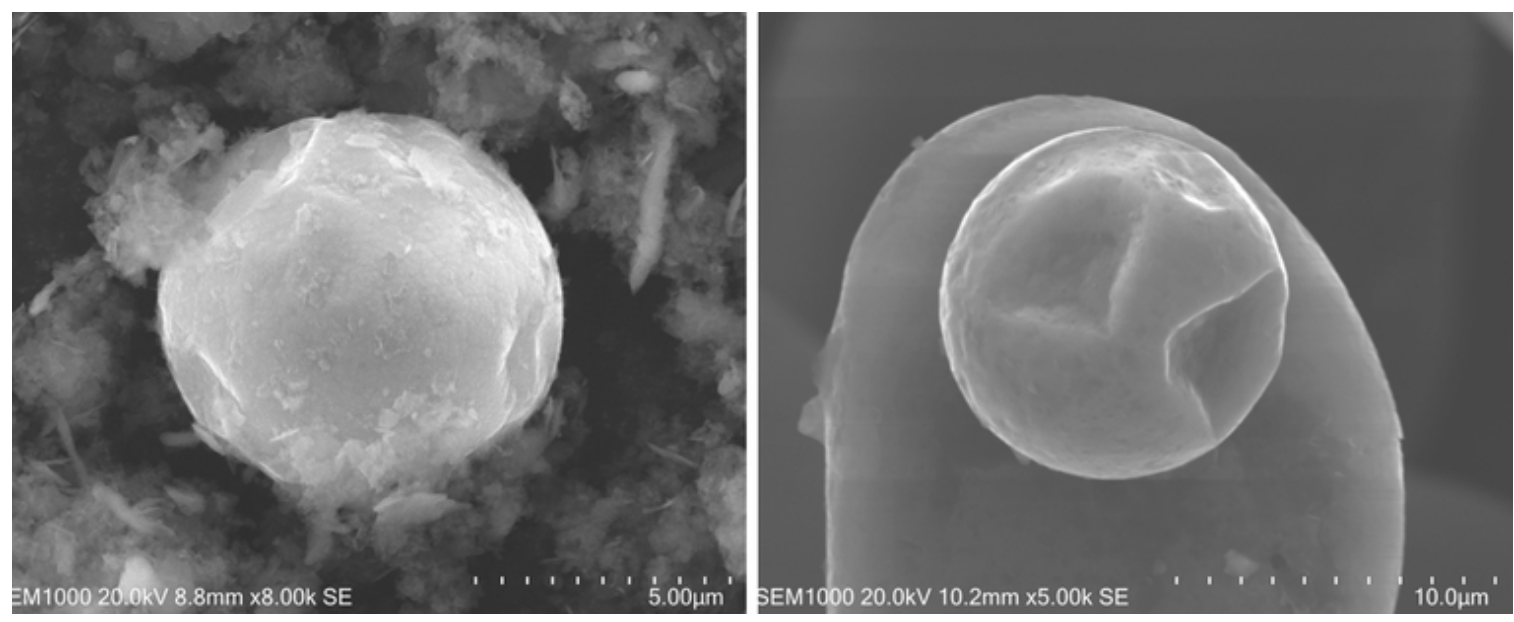

FIGURE 4. Spherical microparticles produced by laser cutting of the thicker tube (left) and the thinner tube (right).

\begin{tabular}{lcccc}
\hline $\begin{array}{l}\text { Particle } \\
\text { size/shape } \\
\text { descriptor }\end{array}$ & $\begin{array}{c}\text { Particles from } \\
\text { the thicker tube } \\
\text { (mean values) }\end{array}$ & $\begin{array}{c}\text { Particles from } \\
\text { the thinner tube } \\
\text { (mean values) }\end{array}$ & $\begin{array}{c}\text { Particles from } \\
\text { the thicker } \\
\text { tube (medians) }\end{array}$ & $\begin{array}{c}\text { Particles from } \\
\text { the thinner } \\
\text { tube (medians) }\end{array}$ \\
\hline $\begin{array}{l}\text { Feret's diameter }[\mathrm{\mu m}] \\
\text { Solidity }\end{array}$ & $114(82)$ & $81(67)$ & 95 & 66 \\
Circularity & $0.91(0.08)$ & $0.87(0.09)$ & 0.93 & 0.89 \\
Roundness & $0.68(0.16)$ & $0.60(0.18)$ & 0.70 & 0.61 \\
\hline
\end{tabular}

TABLE 1. Statistical characteristics of waste powder particles. Numbers in brackets have the meaning of standard deviations. 
Thicker tube
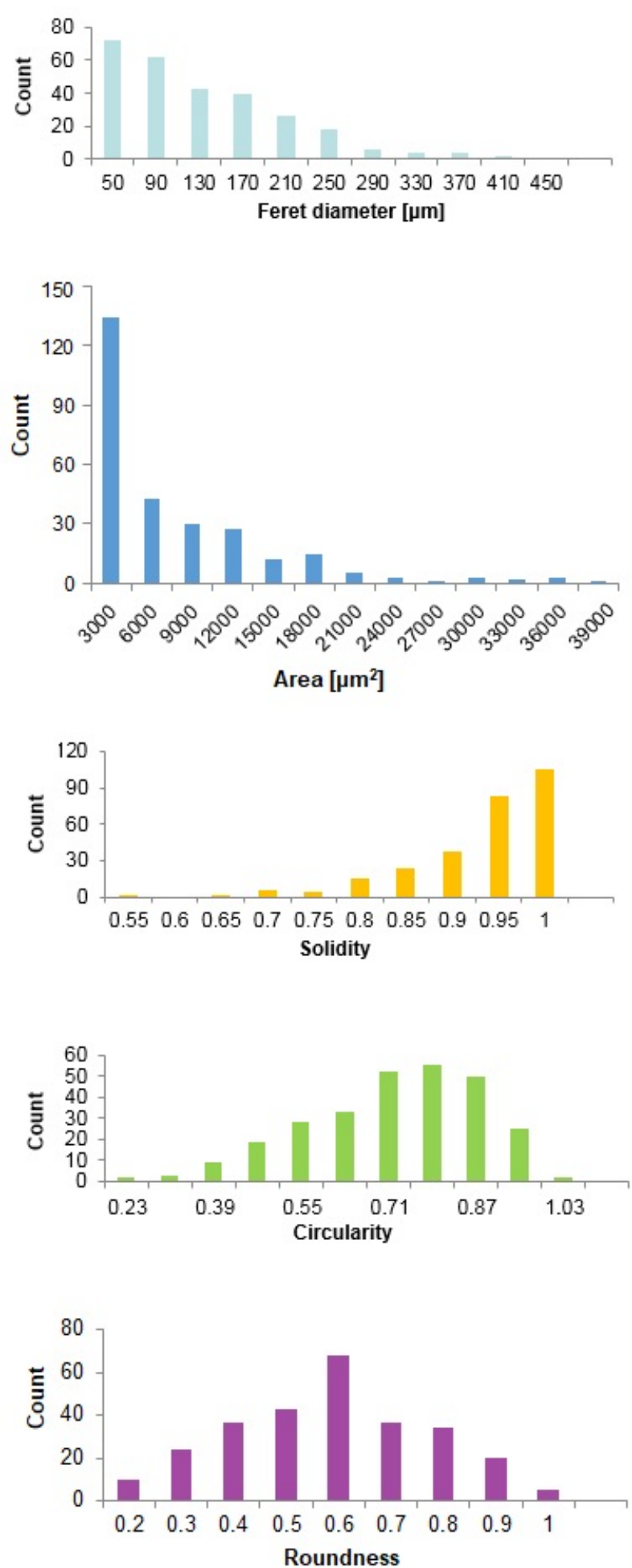

Thinner tube
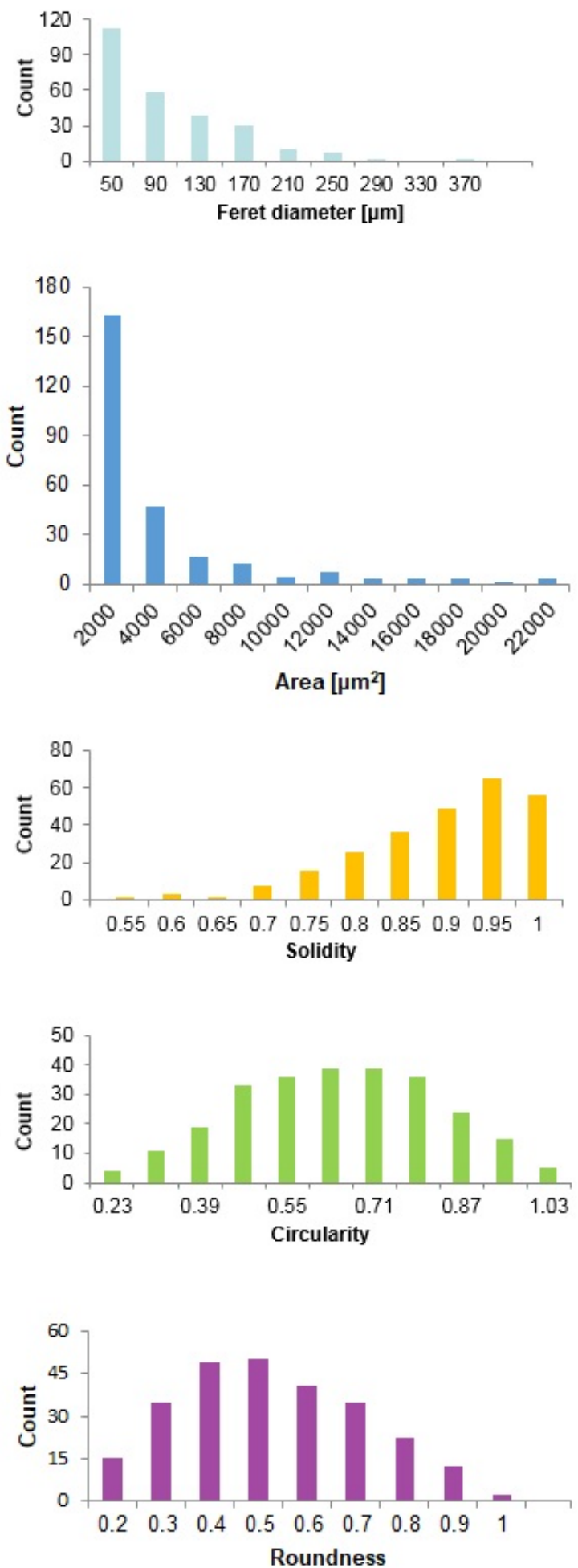

FigURE 5. Histograms describing sizes and shapes of particles obtained by laser cutting of the thicker tube (left) and the thinner tube (right). 


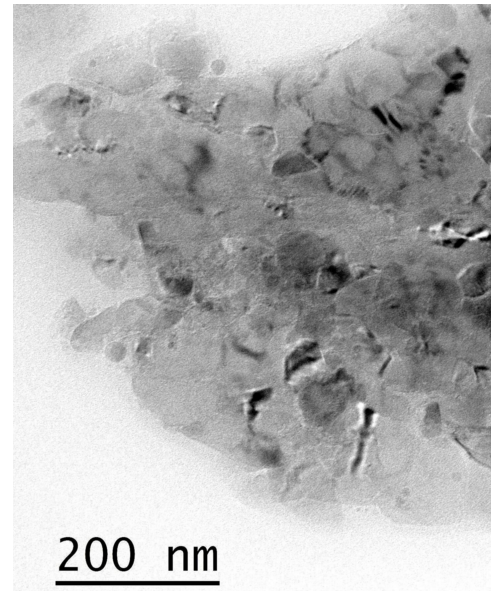

FiguRE 6 . Nanoparticles in the waste powder. Image recorded by a TEM in a bright field.

steel plate. These nanoparticles were spherical with a mean diameter of about $20 \mathrm{~nm}$. Hence it seems that the sizes of AW-3103 alloy and SAE-1010 steel are comparable (of course, it can depend on the processing parameters again), while the AW-3103 alloy nanoparticles have a less spherical shape.

Based on the sizes of the observed AW-3103 alloy micro- and nanoparticles, it can be stated that there is a certain health risk connected especially with inhalation of the waste particles. The smaller the particle size is, the deeper it can penetrate into the respiratory system and thus the greater health problems it can cause. In general, microparticles with an aerodynamic diameter less than $10 \mu \mathrm{m}$ can be inhaled easily into human respiratory system and cause various respiratory diseases, e.g. allergy, chronic obstructive pulmonary diseases or lung cancer. Particles larger than $5 \mu \mathrm{m}$ usually deposit before reaching the lungs, while particles of an aerodynamic diameter between 1 and $5 \mu \mathrm{m}$ are more likely to reach the central and peripheral airways and the alveoli [22. Particles smaller than $2.5 \mu \mathrm{m}$ in an aerodynamic diameter can cause also chronic bronchitis, development of asthma [23], decreased function of lungs, and even premature decease [22].

Ultrafine particles (less than $100 \mathrm{~nm}$ in an aerodynamic diameter) can even penetrate the alveolar epithelium, get into the bloodstream 24] and harm other parts of the body, especially the cardiovascular system. For instance, they may contribute to coronary atherosclerosis and worsen its consequences [22]. Such tiny particles exhibit an enhanced inflammatory potential too [24].

The mentioned health risks connected with microand nanoparticles imply that the described aluminium waste powders should be treated carefully to avoid the emergence of such health problems.

\subsection{ElEmENTAL COMPOSITION ANALYSIS}

Using the EDS, it was found that the waste microparticles contain predominantly aluminium with manganese and iron as trace elements. The tube size has

\begin{tabular}{lc}
\hline Element & Concentration [wt\%] \\
\hline $\mathrm{Mn}$ & $0.90-1.50$ \\
$\mathrm{Fe}$ & $0.0-0.70$ \\
$\mathrm{Si}$ & $0.0-0.50$ \\
$\mathrm{Mg}$ & $0.0-0.30$ \\
$\mathrm{Zn}$ & $0.0-0.20$ \\
$\mathrm{Cr}$ & $0.0-0.10$ \\
$\mathrm{Cu}$ & $0.0-0.10$ \\
$\mathrm{Ti}+\mathrm{Zr}$ & $0.0-0.10$ \\
Others (Total) & $0.0-0.15$ \\
$\mathrm{Al}$ & Balance \\
\hline
\end{tabular}

TABLE 2. Declared elemental composition of AW-3103 alloy [25].

no significant influence on the particles' elemental composition.

The original material of the tubes also contains silicon. Figure 7 shows the typical EDS spectra of the waste microparticles, a laser cut tube surface and a polished tube surface (not affected by laser cutting). The content of silicon on the polished surface is probably overestimated due to its possible contamination from a sandpaper, which was used to polish the sample. Low concentrations of silicon (around $0.3 \mathrm{wt} \%$ ) were detected also in some areas of the laser cut surface, but not everywhere. A reason for this could be an inhomogeneous distribution of silicon on the cut surface, which caused that in some areas, the content of silicon was below the detection limit. A similar situation occurs with iron, which was also detected only in some areas of the laser cut surface.

The declared composition of AW-3103 alloy is shown in Table 2 The given concentrations are in compliance with the values obtained by the EDS measurements. (Only there is a big difference between the declared concentration of $\mathrm{Si}$ and the Si concentration measured on the polished surface, which can be explained by the mentioned sample contamination during its polishing.)

\subsection{Structural ANALYSis}

Phase composition of the waste powder particles was determined using the XRD method. The results confirmed that the particles are composed predominantly of aluminium phase with only a slight presence of other phases. Based on the performed structural analysis using ICDD PDF4+ database, the other phases were identified as magnetite $\left(\mathrm{Fe}_{3} \mathrm{O}_{4}-\mathrm{ICDD}\right.$ PDF card number 04-008-4512), austenite ( $\gamma$-Fe - ICDD PDF card number 04-020-7293) and graphite (ICDD PDF card number 04-016-6288). Diffraction patterns of powders from both tubes are shown in Figure 8 . all six strongest peaks (marked with green triangles) belong to the aluminium phase.

\section{Conclusions}

The presented research revealed that waste powder microparticles generated during laser cutting of AW-3103 

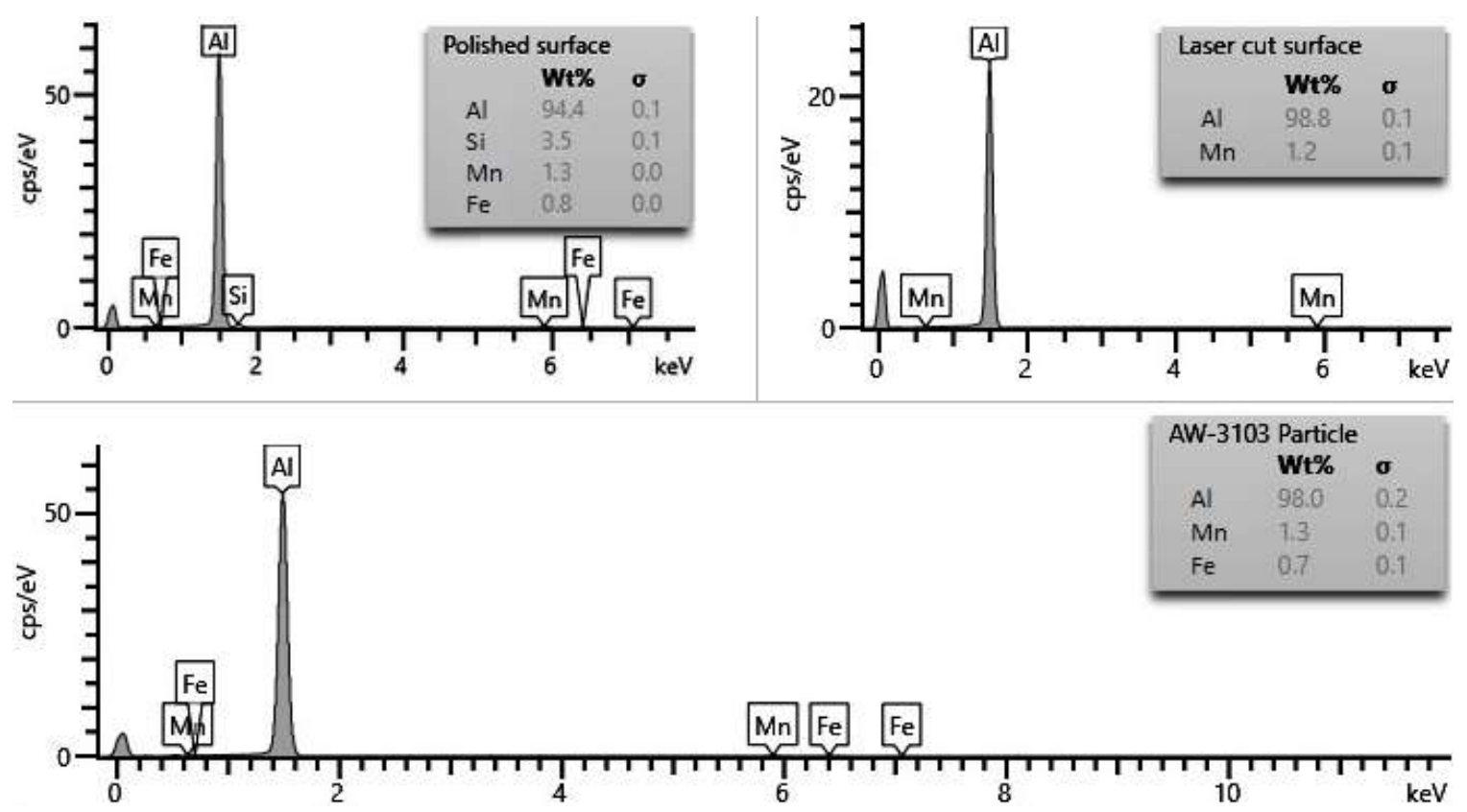

FIGURE 7. EDS summary spectra of the polished tube surface (top left), laser cut tube surface (top right) and a waste particle surface (bottom).

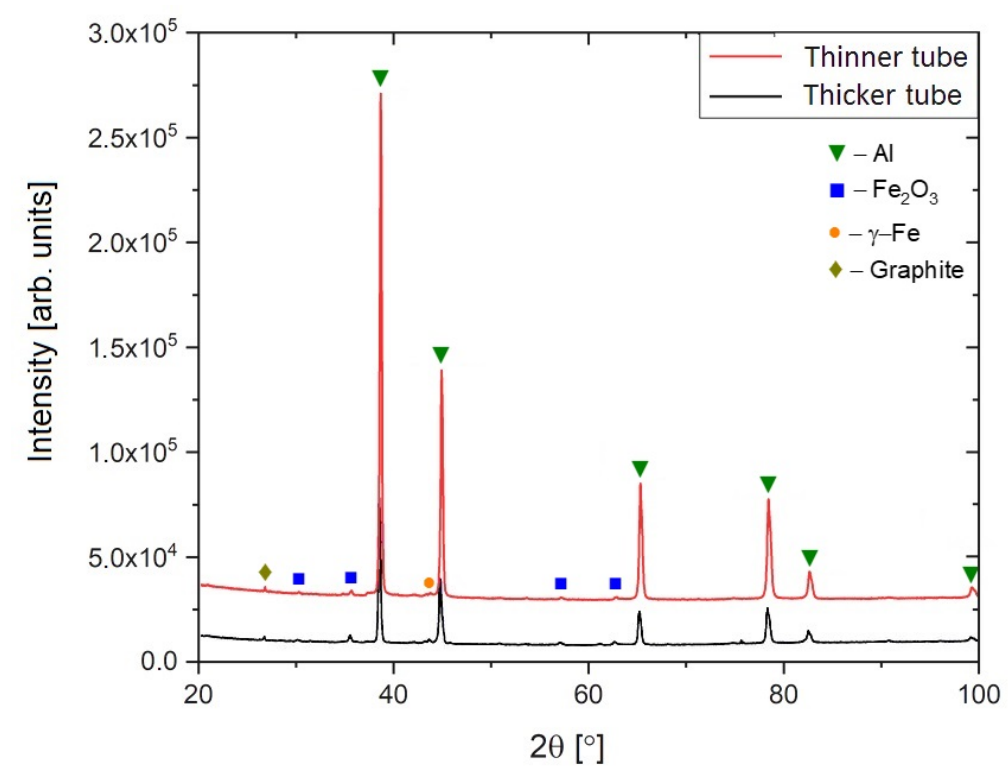

FIGURE 8. X-ray diffraction patterns of the waste products obtained by laser cutting of the thicker tube (black curve) and the thinner tube (red curve). 
alloy are mostly plate-like with Feret's diameters up to hundreds of $\mu \mathrm{m}$, but some smaller bumpy spheres are also present in the powder. The microparticles consist of almost pure aluminium with only a slight presence of other phases (magnetite, austenite and graphite). The average size of the microparticles increases with increasing thickness of the aluminium tube from which they originate, while there is only a little impact of the tube thickness on their shape. The chemical composition of the particles is not affected by the tube dimensions. The waste powder characteristics suggest that this material has a potential to be used, for instance, as an input material for additive manufacturing.

Furthermore, the presence of nanoscale particles (with an aerodynamic diameter below $150 \mathrm{~nm}$ ) was revealed in the waste powder. Inhalation of the observed micro- and especially nanoparticles can cause various health problems, such as cancer or damage to the cardiovascular system.

Future research should be focused on studying waste powders originating from other types of alloys and on assessing the impact of various cutting process parameters on both the powders and the cut surfaces.

\section{ACKNOWLEDGEMENTS}

The presented research was financially supported by the Specific research project 2107/2019 at the Faculty of Science, University of Hradec Králové.

\section{REFERENCES}

[1] A. K. Dubey, V. Yadava. Laser beam machining - A review. International Journal of Machine Tools and Manufacture 48(6):609 - 628, 2008. DOI:10.1016/j.ijmachtools.2007.10.017

[2] L. Yang, J. Wei, Z. Ma, et al. The fabrication of micro/nano structures by laser machining.

Nanomaterials 9(12):1789, 2019. DOI:10.3390/nano9121789.

[3] D. Teixidor, J. Ciurana, C. Rodriguez. Dross formation and process parameters analysis of fibre laser cutting of stainless steel thin sheets. The International Journal of Advanced Manufacturing Technology 71(9 12):1611 - 1621, 2014. DOI:10.1007/s00170-013-5599-0.

[4] A. Amulevicius, K. Mazeika, C. Sipavicius. Oxidation of stainless steel by laser cutting. Acta Physica Polonica Series a 115:880 - 885, 2009. DOI:10.12693/APhysPolA.115.880.

[5] K. Krot, E. Chlebus, B. Kuźnicka. Laser cutting of composite sandwich structures. Archives of Civil and Mechanical Engineering 17(3):545 - 554, 2017. DOI:10.1016/j.acme.2016.12.007

[6] A. Khan, J. Blackburn. Laser size reduction of radioactively contaminated structures. Journal of Laser Applications 30(3):032607, 2018. DOI:10.2351/1.5040650

[7] A. Lisiecki, A. Kurc-Lisiecka. Automated laser welding of AISI 304 stainless steel by disk laser. Archives of Metallurgy and Materials 63(4):1663 - 1672, 2018. DOI:10.24425/amm.2018.125091
[8] Z. Brytan. The erosion resistance and microstructure evaluation of laser surface alloyed sintered stainless steels. Archives of Metallurgy and Materials 63(4):2039 - 2049, 2018. DOI:10.24425/amm.2018.125141

[9] B. S. Yilbas, B. J. A. Aleem. Dross formation during laser cutting process. Journal of Physics D: Applied Physics 39(7):1451 - 1461, 2006. DOI:10.1088/0022-3727/39/7/017.

[10] A. Riveiro, F. Quintero, F. Lusquiños, et al. Study of melt flow dynamics and influence on quality for $\mathrm{CO} 2$ laser fusion cutting. Journal of Physics D: Applied Physics 44(13):135501, 2011. DOI:10.1088/0022-3727/44/13/135501

[11] L. Lobo, K. Williams, J. Tyrer. The effect of laser processing parameters on the particulate generated during the cutting of thin mild steel sheet. Proceedings of The Institution of Mechanical Engineers Part $C$ journal of Mechanical Engineering Science 216(3):301 313, 2002. DOI:10.1243/0954406021525016.

[12] R. Mercader, S. Marchetti, F. Bengoa, et al. Characterization of scraps produced by the industrial laser cutting of steels. Hyperfine Interactions 195(1 3):249 - 255, 2010. DOI:10.1007/978-3-642-10764-1_38

[13] A. Lopez, E. Assunção, I. Pires, L. Quintino. Secondary emissions during fiber laser cutting of nuclear material. Nuclear Engineering and Design 315:69 - 76, 2017. DOI:10.1016/j.nucengdes.2017.02.012.

[14] J. Souza, C. Motta, T. Machado, et al. Analysis of metallic waste from laser cutting for utilization in parts manufactured by conventional powder metallurgy. International Journal of Research in Engineering and Science 4(11):1, 2016.

[15] K. Elihn, P. Berg. Ultrafine particle characteristics in seven industrial plants. The Annals of Occupational Hygiene 53(5):475 - 484, 2009. DOI:10.1093/annhyg/mep033

[16] T. Ferreira, W. Rasband. ImageJ User Guide: IJ 1.46r. ImageJ: Image Processing and Analysis in Java. https: //imagej.nih.gov/ij/docs/guide/user-guide.pdf 2012. Accessed: 17 April 2019.

[17] J. Powell, A. Ivarson, C. Magnusson. Laser cutting of steels: A physical and chemical analysis of the particles ejected during cutting. Part II. Journal of Laser Applications 5(1):25 - 31, 1993. DOI:10.2351/1.4745321.

[18] E. Cabanillas, M. Creus, R. Mercader. Microscopic spheroidal particles obtained by laser cutting. Journal of Materials Science 40(2):519 - 522, 2005. DOI:10.1007/s10853-005-6118-y

[19] E. Cabanillas. Transmission electron microscopy observation of nanoparticles obtained by cutting power laser. Journal of Materials Science 39(11):3821 - 3823, 2004. DOI:10.1023/B:JMSC.0000030748.97677.81

[20] Malvern Panalytical. Material characterization solutions for powder metallugy. https://www.malvernpanalytical.com/en/assets/ MRK2319_tcm50-55142.pdf, 2017. Accessed: 18 September 2019. 
[21] J. Liu, J. Silveira, R. Groarke, et al. Effect of powder metallurgy synthesis parameters for pure aluminium on resultant mechanical properties. International Journal of Material Forming 12:79 - 87, 2019. DOI:10.1007/s12289-018-1408-5.

[22] D. Vallero. Fundamentals of air pollution. Academic Press, Waltham, 5th edn., 2014.

[23] G. Yu, F. Wang, J. Hu, et al. Value assessment of health losses caused by PM2.5 in Changsha City, China. International Journal of Environmental Research and Public Health 16(11):2063, 2019. DOI:10.3390/ijerph16112063
[24] M. Elmes, M. Gasparon. Sampling and single particle analysis for the chemical characterisation of fine atmospheric particulates: A review. Journal of Environmental Management 202:137 - 150, 2017. DOI:10.1016/j.jenvman.2017.06.067.

[25] Aalco. Aluminium alloy 3103 h14 datasheet. http://www. aalco.co.uk/datasheets/ Aluminium-Alloy-3103-H14-Sheet_298.ashx 2020. Accessed: 21 July 2020 